\title{
Current controversies in minimally invasive urologic oncology
}

Over the past three decades, rapid development and application of minimally invasive surgical techniques has fundamentally altered the way urologists care for patients with urologic malignancies. The short-term gains of decreased blood loss, improved convalescence, and improved cosmesis have resulted in the rapid adoption of laparoscopy and robotics, and as a result the vast majority of prostate and kidney surgeries are now performed using the robotic platform in the absence of true long-term outcome improvement or cost benefits.

In this chapter, a series of review articles highlight current controversies surrounding the adoption of minimally invasive surgical techniques for urologic malignancies and summarize the existing literature supporting their use. For well-established techniques such as robotic prostatectomy we evaluate the comparative effectiveness of open and robotic surgery, describe recent innovations in surgical technique, and report emerging applications for locally advanced and metastatic disease. Regarding upper retroperitoneal surgery, we review contemporary outcomes utilizing retroperitoneoscopic approaches for nephron sparing surgery and robotic approaches to IVC thrombectomy and reconstruction, robotic approaches to retroperitoneal lymph node dissection, and compare open and minimally invasive approaches to adrenal surgery. For pelvic surgeries, we evaluate the adoption of the robotic platform for patients undergoing radical cystoprostatectomy, and the technical considerations for intracorporeal urinary diversion, as well as explore and compare outcomes in patients with penile cancer undergoing open and minimally invasive inguinal lymph node dissection.

Finally, acknowledging that continual reassessment and re-evaluation are critical to the adoption of any novel technologies, we report on the contemporary experience of emerging physician led surgical quality collaboratives and ongoing quality improvement efforts to improve adherence to evidence-based guidelines and opioid stewardship. As the collective experience accumulates with minimally invasive surgery, it is only natural that increased physician involvement in the development and assessment of evidence-based performance metrics will be essential to improve the quality of urologic oncologic care delivery.

We would like to humbly thank the Journal for the opportunity to edit this special series, as well as all the authors for their thoughtful, well researched contributions.

\section{Acknowledgments}

Funding: None.

\section{Footnote}

Provenance and Peer Review: This article was commissioned by the editorial office, Translational Andrology and Urology for the series "Controversies in Minimally Invasive Urologic Oncology". The article did not undergo external peer review.

Conflicts of Interest: Both authors have completed the ICMJE uniform disclosure form (available at http://dx.doi.org/10.21037/ tau-21-258). The series "Controversies in Minimally Invasive Urologic Oncology" was commissioned by the editorial office without any funding or sponsorship. MCS and JJT served as the unpaid Guest Editors of the series. The authors have no other conflicts of interest to declare.

Ethical Statement: The authors are accountable for all aspects of the work in ensuring that questions related to the accuracy or integrity of any part of the work are appropriately investigated and resolved.

Open Access Statement: This is an Open Access article distributed in accordance with the Creative Commons AttributionNonCommercial-NoDerivs 4.0 International License (CC BY-NC-ND 4.0), which permits the non-commercial replication and distribution of the article with the strict proviso that no changes or edits are made and the original work is properly cited (including links to both the formal publication through the relevant DOI and the license). See: https://creativecommons.org/ licenses/by-nc-nd/4.0/. 


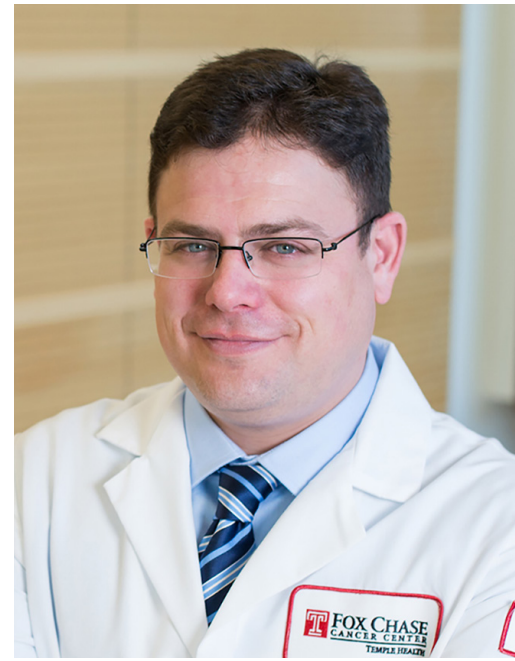

Marc C. Smaldone

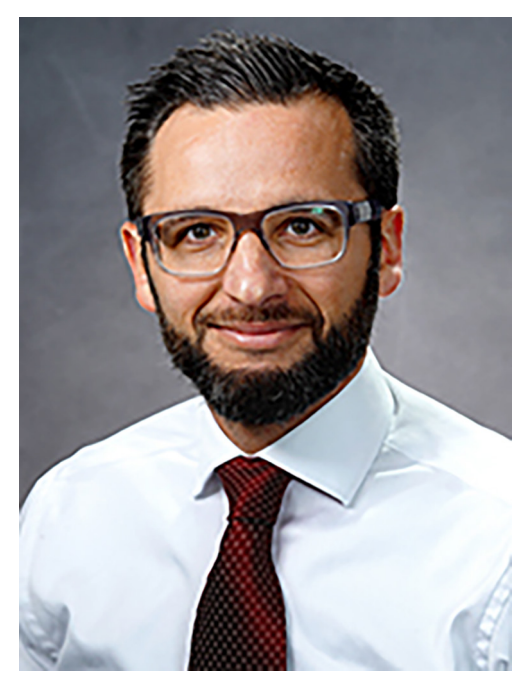

Jeffrey J. Tomaszewski

Marc C. Smaldone, MD, MSHP Fox Chase Cancer Center, Philadelphia, PA, USA.

(Email: Marc.smaldone@fccc.edu)

Jeffrey J. Tomaszewski, MD

MD Anderson Cancer Center at Cooper, Camden, N7, USA.

(Email: Tomaszewski-jeffrey@cooperbealth.edu)

Submitted Mar 21, 2021. Accepted for publication Mar 29, 2021. doi: $10.21037 /$ tau-21-258

View this article at: http://dx.doi.org/10.21037/tau-21-258
Cite this article as: Smaldone MC, Tomaszewski JJ. Current controversies in minimally invasive urologic oncology. Transl Androl Urol 2021;10(5):2149-2150. doi: 10.21037/tau-21-258 